\title{
Biofilm production by Aureobasidium pullulans improves biocontrol against sour rot in citrus
}

\author{
Mariana Nadjara Klein ${ }^{\text {a }}$, Katia Cristina Kupper ${ }^{\text {b, * }}$ \\ a Faculdade de Ciências Agrárias e Veterinárias, UNESP - Universidade Estadual Paulista, "Julio de Mesquita Filho". Postgraduate in Agricultural \\ Microbiology, CEP 14884-900, Jaboticabal, SP, Brazil

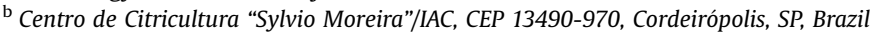

\section{A R T I C L E I N F O}

\section{Article history:}

Received 16 November 2016

Received in revised form 10 July 2017

Accepted 13 July 2017

Available online 18 July 2017

\section{Keywords:}

Ammonium sulfate

Biological control

Geotrichum citri-aurantii

Electron microscopy

\begin{abstract}
A B S T R A C T
The biocontrol efficiency of Aureobasidium pullulans strain ACBL-77 against Geotrichum citri-aurantii, causal agent of sour rot in citrus, and their interactions were evaluated. For this, were evaluated the incorporation of nutrients in optimizing the antagonistic activity of the yeast, the competition for nutrients between microorganisms, the effect of nutrients on yeast cell and biofilm production and their correlation in the biocontrol of disease, the survival of yeast in citrus fruits and the interaction between microorganisms using scanning electron microscopy. Micronutrients (boric acid, cobalt chloride and ammonium molybdate) favoured the antagonistic action of $A$. pullulans. Ammonium sulfate $1 \%$ and sucrose $0.5 \%$ favoured the yeast during the competition between the microorganisms. The addition of ammonium sulfate $(1 \%)$ in the yeast culture stimulated biofilm production and increased the antagonistic activity against the disease, as also allowed the better survival of yeast in wounded sites of citrus fruit. The yeast was found to be able to form biofilms on citrus, deforming the pathogen hyphae. These results showed the importance of the addition of nutrients in A. pullulans based-formulations when aiming for their use on a commercial scale. This is the first report of a positive correlation between the increase in the quantity of biofilm produced by A. pullulans, with increased antagonistic activity.
\end{abstract}

(ㄷ) 2017 Elsevier Ltd. All rights reserved.

\section{Introduction}

Postharvest diseases, especially those caused by fungal pathogens, present significant economic losses and furthermore, some decay fungi also produce mycotoxins that represent a risk to human health (Liu et al., 2017).

During storage, citrus fruits are exposed to the pathogens that can infect the host through wounds that occur during the harvest, transport and handling of fruit (Karim et al., 2015). The sour rot caused by the fungus Geotrichum citri-aurantii (Ferraris) (Butler et al., 1988) is one of the most important diseases of citrus crops, affecting all species and cultivars in all producing countries (Talibi et al., 2012).

This disease is not controlled by any of the fungicides that are registered for the control of post-harvest diseases in citrus fruits during processing in packing houses, such as imazalil, thiabendazole, pyrimethanil, and fludioxonil (Liu et al., 2009; Zhou et al.,

\footnotetext{
* Corresponding author.

E-mail address: katia@centrodecitricultura.br (K.C. Kupper).
}

2014). The fungicides guazatine and propiconazole can control sour rot, but these fungicides are not registered in many countries, including Brazil (Brown, 1988; McKay et al., 2012). The sodium ophenylphenate (SOPP) has activity against sour rot and it is registered for use in the post-harvest. However, this product presents risk of fruit damage (Feng et al., 2011) and, in the Brazil, specially, this fungicide is on the national list of carcinogenic agents for humans (Brazil, 2014). According to Hao et al. (2010), the failure to register a product for the control of this disease has become a serious problem for the marketing of quality citrus fruit. Therefore, developing control strategies for G. citri-aurantii has been a challenge for researchers.

In this context, the use of yeast has shown promising results, especially in the control of disease in post-harvest fruit (Parafati et al., 2015; Spadaro and Droby, 2016). Aureobasidium pullulans De Bary (Arnaud), strain ACBL-77, has been effective in the control of sour rot of citrus, producing chitinase and killer activity as possible mechanisms of action against the phytopathogen (Ferraz et al., 2016).

It is key to know the mechanisms of action of antagonists for the development of control management technologies during the post- 
harvest phase as well as for the development of commercial formulations and application methods to maximize the use of biological control agents on a large scale (Parafati et al., 2015; Spadaro and Droby, 2016).

Data in the literature have shown that A. pullulans has several mechanisms of action against plant pathogens, such as competition for space and nutrients (Bencheqroun et al., 2007); the production of thermostable antifungal compounds (Adikaram et al., 2002), hydrolytic enzymes (Zhang et al., 2010), protease (Zhang et al., 2012.), volatile and cell-free compounds (Di Francesco et al., 2015a, 2015b.), killer toxins (Ferraz et al., 2016.), and the antibiotic aureobasidin (AbA) (Liu et al., 2007); and the induction of plant defence responses (Ippolito et al., 2000).

In addition, $A$. pullulans strains may produce secondary metabolites such as extracellular polysaccharides (EPSs). The amount of these EPSs produced can be affected by the concentration of different nitrogen sources during the cultivation of the microorganism (Jiang et al., 2011). In this regard, according to Ravella et al. (2010), microorganisms aggregate and form a biofilm by creating a network of cells and EPSs, forming a gel that acts to keep the microorganisms in the biofilm attached, causing adhesion to surfaces and protecting it from adverse conditions.

Many factors may influence biofilm formation by yeast and the primary initial attachment of the organism to plant tissue, which is mediated by specific proteins anchored by glycosylphosphatidylinositol present in the yeast cell wall (Finkel and Mitchell, 2011; Pu et al., 2014).

The production of pullulan, an EPS produced by A. pullulans, can be stimulated by the addition of ammonium sulfate or ammonium nitrate (Bulmer et al., 1987; Ravella et al., 2010) to the culture medium, influencing the production, composition and efficiency of these EPSs. Therefore, to improve the viability and biocontrol efficiency of this agent during post-harvest, studies should be conducted in combination with nutrients to optimize its antagonistic performance (Vero et al., 2009).

In this work, we evaluated (i) the incorporation of nutritional sources to optimize the antagonistic activity of the yeast; (ii) the competition for nutrients between the microorganisms; (iii) the effect of the nutrients in yeast cell and biofilm production and their correlation with the biocontrol of the pathogen; (iv) the survival of the yeast in citrus fruits and, finally (v) the interaction between the microorganisms using scanning electron microscopy.

\section{Materials and methods}

\subsection{Microorganisms}

The Aureobasidium pullulans strain ACBL-77 was obtained from citrus (Ferraz et al., 2016), and the Geotrichum citri-aurantii strain was obtained from citrus fruit showing symptoms of disease. Both isolates were identified by molecular technique and are deposited in the microorganism collection of the APTA Center Citrus "Sylvio Moreira"/IAC, Cordeirópolis, state of São Paulo, Brazil.

\subsection{Effect of nutrient sources on the antagonistic activity of Aureobasidium pullulans}

This experiment aimed to determine the effects of the addition of nitrogen and micronutrient sources to potato dextrose agar medium (PDA) used in the cultivation of strain ACBL-77, measuring the inhibition of mycelial growth of G. citri-aurantii. The sources of nitrogen used were urea $\left(\mathrm{CH}_{4} \mathrm{~N}_{2} \mathrm{O}\right)$, ammonium sulfate $\left(\left(\mathrm{NH}_{4}\right)_{2} \mathrm{SO}_{4}\right)$, ammonium nitrate $\left(\mathrm{NH}_{4} \mathrm{NO}_{3}\right)$, tryptone and potassium nitrate $\left(\mathrm{KNO}_{3}\right)$ at concentrations of $0.02,0.1$ and $0.5 \%(\mathrm{w} / \mathrm{v})$. The micronutrients tested were boric acid $\left(\mathrm{H}_{3} \mathrm{BO}_{4}\right)$, copper sulfate
$\left(\mathrm{CuSO}_{4} \cdot 5 \mathrm{H}_{2} \mathrm{O}\right)$, manganese sulfate $\left(\mathrm{MnSO}_{4} \cdot \mathrm{H}_{2} \mathrm{O}\right)$, cobalt chloride $\left(\mathrm{CoCl}_{2} \cdot 12 \mathrm{H}_{2} \mathrm{O}\right)$, ferric chloride $\left(\mathrm{FeCl}_{3}\right)$, zinc sulfate $\left(\mathrm{ZnSO}_{4}\right)$ and ammonium molybdate $\left(\left(\mathrm{NH}_{4}\right)_{6} \mathrm{Mo}_{7} \mathrm{O}_{24} \cdot 4 \mathrm{H}_{2} \mathrm{O}\right)$ with final concentrations of $0.05,0.2$ and $1 \mathrm{mM}$, respectively (this protocol was adapted from Wiyono et al., 2008).

Fifty millilitres of sterile liquid potato-dextrose broth $(\mathrm{PDB})+$ nutrient plus $1 \mathrm{~mL}$ of yeast suspension $\left(1 \times 10^{7}\right.$ cells $\left.\mathrm{mL}^{-1}\right)$ was added to Erlenmeyer flasks. The cultures were incubated at $25{ }^{\circ} \mathrm{C}$ on a shaker at $150 \mathrm{rpm}$ for $72 \mathrm{~h}$. After incubation, the fermentation broths were filtered through sterile filter paper, and later, samples of $10 \mathrm{~mL}$ of each filtrate were transferred to Erlenmeyer flasks (250 mL capacity) containing $90 \mathrm{~mL}$ of melted PDA. Before autoclaving the culture medium, the $\mathrm{pH}$ was then adjusted to 5.5 with perchloric acid $0.1 \%$, and the media were poured into Petri dishes. After the media solidified, a 5-mm G. citri-aurantii culture disk was placed in the center of each plate. For the control, G. citri-aurantii was grown on PDA medium without nutrients.

The Petri plates were incubated in a BOD (Biochemical Oxygen Demand) chamber at $25^{\circ} \mathrm{C}$ for 9 days with a $12 \mathrm{~h}$ photoperiod, and the growth of G. citri-aurantii was assessed by measuring the mean diameter of each colony in two perpendicular directions.

The nutrients that were most efficient in controlling the mycelial growth of G. citri-aurantii were used in combination to optimize the antagonistic activity of the yeast isolate.

The best nutrients were also evaluated individually to determine their effects on the mycelial growth of the pathogen. To this end, we followed the same methodology described above, but without the presence of yeast, to observe the direct effects of the nutrients on the development of the pathogen.

A completely randomized design with six replicates was used in all the experiments.

\subsection{Competition for nutrients between Aureobasidium pullulans and Geotrichum citri-aurantii}

For the study of competition for nutrients between the yeast and the phytopathogen, agar-coated microscope slides were prepared with different sources of nitrogen (leucine, phenylalanine, proline and ammonium sulfate at concentrations of 0.5 and 1.0\%), carbon (sucrose, maltose, galactose and fructose at concentrations of 0.5 and 1.0\%) (Zhang et al., 2011) and micronutrients (boric acid, cobalt chloride and ammonium molybdate chloride at a concentration of $1 \mathrm{mM})$, according to the methodology of Ferraz et al. (2016).

Ten microliters of a G. citri-aurantii suspension $\left(1 \times 10^{5}\right.$ conidia $\left.\mathrm{mL}^{-1}\right)$ and $10 \mu \mathrm{L}$ of a yeast suspension $\left(1 \times 10^{7}\right.$ cells $\left.\mathrm{mL}^{-1}\right)$ were applied onto pre-marked locations on the slides with agar-water, with the addition of different nutrient sources, and the cultures were incubated in a BOD chamber at $25^{\circ} \mathrm{C}$ with a $12 \mathrm{~h}$ photoperiod for $16 \mathrm{~h}$. Only agar-water was used for the control. Nutrient competition was assessed by counting the number of germinated conidia among 100 randomly selected conidia. The conidia were considered fully germinated when the length of the germ tube was at least the size of the swollen conidia. A completely randomized design with eight replicates was used in all the experiments.

\subsection{Effect of nutrient sources in the culture medium on the production of viable cells by Aureobasidium pullulans}

Based on the results of the previous experiments, the best nutrients were chosen: ammonium sulfate $1 \%$, sucrose $0.5 \%$, boric acid $1 \mathrm{mM}$, cobalt chloride $1 \mathrm{mM}$ and ammonium molybdate $1 \mathrm{mM}$.

One millilitre of the yeast suspension $\left(1 \times 10^{7}\right.$ cells $\left.\mathrm{mL}^{-1}\right)$ was transferred to Erlenmeyer flasks containing $99 \mathrm{~mL}$ of YMM medium (containing $1 \mathrm{~mL}$ of stock solution $1 \% \mathrm{MgSO}_{4} \cdot 7 \mathrm{H}_{2} \mathrm{O}, 2.2 \%$ $\mathrm{CaCl}_{2} \cdot 5 \mathrm{H}_{2} \mathrm{O}, 2.2 \% \mathrm{~K}_{2} \mathrm{HPO}_{4}, 0.2 \% \mathrm{FeCl}_{3}$ in $0.1 \mathrm{M} \mathrm{HCl}+10 \mathrm{~mL}$ of $11 \%$ 
$\mathrm{C}_{5} \mathrm{H}_{8} \mathrm{NO}_{4} \mathrm{Na}+100 \mathrm{~mL} 10 \%$ glucose, with the volume adjusted to $1 \mathrm{~L}$ ) to observe the direct effect of the nutrients. For the control, the yeast was cultivated in YMM medium without the addition of nutrients.

The cultures were incubated at $25{ }^{\circ} \mathrm{C}$ on a shaker at $150 \mathrm{rpm}$. One millilitre was removed from each culture at different times: 0 , $12,24,36,48,72,96,120,144,168$ and $192 \mathrm{~h}$ using the decimal dilution technique, and these samples were then plated on PDA media. The evaluation was performed by counting the colonyforming units $48 \mathrm{~h}$ after plating. The density of the yeast was expressed in $\log _{10} \mathrm{CFU} \mathrm{mL} \mathrm{m}^{-1}$. A completely randomized design with four replicates was used in all the experiments.

\subsection{Effects of nutrient sources on biofilm production by Aureobasidium pullulans}

Biofilm production was evaluated following the partial modification of a previously described procedure (O'Toole and Kolter, 1998). The crystal violet (CV) methodology was used to quantify the biofilm formation by yeast. A suspension $(20 \mathrm{~mL})$ of $A$. pullulans $\left(1 \times 10^{6}\right.$ cells $\left.\mathrm{mL}^{-1}\right)$ was transferred to Erlenmeyer flasks containing $180 \mathrm{~mL}$ of $\mathrm{BD}$. This culture was incubated at $25{ }^{\circ} \mathrm{C}$ on a shaker at $150 \mathrm{rpm}$ for $72 \mathrm{~h}$. The yeast concentration was adjusted to $1 \times 10^{7}$ cells $\mathrm{mL}^{-1}$ and was used as the initial inoculum.

Aliquots of $100 \mu \mathrm{L}$ of the initial inoculum were added to tubes containing $10 \mathrm{~mL}$ of YMM medium plus nutrients (ammonium sulfate $1 \%$, sucrose $0.5 \%$, boric acid $1 \mathrm{mM}$, cobalt chloride $1 \mathrm{mM}$ and ammonium molybdate $1 \mathrm{mM}$ ). For the control (blank), YMM without yeast growth was used. The cultures were incubated at $25{ }^{\circ} \mathrm{C}$ on a shaker at $150 \mathrm{rpm}$ until the stationary growth phase according to the data from the previous experiment. A total of eight tubes were used as replicates.

For the quantification of the biofilm, the medium was gently removed, and the tubes were washed with $0.9 \% \mathrm{NaCl}$ and stained with $0.1 \% \mathrm{CV}$. After incubation for $30 \mathrm{~min}$, the unbound $\mathrm{CV}$ was removed, and the tubes were washed three times with distilled water. The CV in each tube was solubilized by the addition of $10 \mathrm{~mL}$ of ethanol 70\%, and the absorbance (A) was measured at $590 \mathrm{~nm}$ (UV/Vis Spectrometer Lambda Bio, Perkin Elmer).

Another experiment was conducted under the same conditions by adding $100 \mu \mathrm{L}$ of a $\mathrm{G}$. citri-aurantii suspension $\left(1 \times 10^{5}\right.$ conidia $\mathrm{mL}^{-1}$ ) cultivated in BD for 5 days at $150 \mathrm{rpm}$ alone or in combination with an aliquot of yeast to tubes containing YMM medium with different nutrients added or not to verify the influence of fungal presence on biofilm formation by the yeast strain.

\subsection{Antifungal activity of Aureobasidium pullulans in vivo}

Citrus fruits were obtained from commercial orchards in Limeira, Brazil. Surface disinfected by dipping for $1 \mathrm{~min}$ in $1 \%(\mathrm{w} / \mathrm{v})$ of sodium hypoclorite $(\mathrm{NaClO})$ solution, rinsed with sterile distilled water and then air-dried.

Commercially mature Pera orange (Citrus sinensis (L.) Osbeck) fruits were obtained from a packing house in the city of Limeira, São Paulo, Brazil. Citrus fruits had not received any pre-harvest fungicide treatment. Healthy and homogenous citrus were selected and randomly assigned to different treatments. Before inoculation and treatment, fruits were washed with neutral detergent, and superficially disinfected with Dioxiplus ${ }^{\circledR}$ (stabilizing chlorine dioxide base, $2 \mathrm{~mL} / \mathrm{L}$ ) for $2 \mathrm{~min}$ and then rinsed in distilled water to eliminate the product. The fruits were wounded to a depth of $3 \mathrm{~mm}$ at two equidistant points in the median region with sterile needles, and $20 \mu \mathrm{L}$ of a $G$. citri-aurantii conidial suspension $\left(1 \times 10^{5}\right.$ conidia $\mathrm{mL}^{-1}$ ) was inoculated into the wounded area, which was treated $24 \mathrm{~h}$ later with the yeast (the curative treatment). For the preventive treatment, the fruits were wounded, treated with the yeast and then inoculated with the pathogen $24 \mathrm{~h}$ later.

For the treatments, a suspension of the strain ACBL-77 containing $1 \times 10^{7}$ cells $\mathrm{mL}^{-1}$ adjusted by a direct microscopic count using a Neubauer's Chamber, obtained from the yeast colonies after culturing them on PDA medium for $48 \mathrm{~h}$ was transferred into Erlenmeyer flasks containing $100 \mathrm{~mL}$ YMM medium with different nutrients added. Therefore, the treatments were (i) only YMM; (ii) YMM + ammonium sulfate $1 \%$; (iii) YMM + sucrose $0.5 \%$; (iv) YMM + boric acid1 $\mathrm{mM}$; (v) YMM + cobalt chloride $1 \mathrm{mM}$ and (vi) YMM + ammonium molybdate $1 \mathrm{mM}$. The bottles were then subjected to constant agitation until the stationary phase according to the results obtained in item 2.3. The final concentration of yeast in all treatments was $1 \times 10^{7}$ cells $/ \mathrm{mL}^{-1}$. The fungicide Thiabendazole $^{\circledR}(2.0 \mathrm{~mL} / \mathrm{L})$ was included as a treatment; although it is not effective in controlling the disease, this product is widely used in packing houses in Brazil. The control fruits were treated with sterile distilled water instead of another treatment.

After inoculation with $G$. citri-aurantii and the application of treatments, the fruits were stored for 15 days at $25 \pm 3{ }^{\circ} \mathrm{C}$ and $90 \pm 3 \%$ relative humidity $(\mathrm{RH})$. The incidence was expressed as the percentage of infected fruits observed on day 15. To analyse the in vivo test, the treatments were arranged in a completely random design, with each treatment consisting of three replicates with 25 fruits per replicate.

\subsection{Colonization of citrus wounds by Aureobasidium pullulans}

The ability of $A$. pullulans cells to survive and multiply in wounded sites of citrus fruit was determined as follows. Commercially mature Pera orange fruits were disinfected with $70 \%$ ethanol, rinsed in fresh water, wounded, and injected with $30 \mu \mathrm{L}$ of a washed cell suspension of $A$. pullulans at $1 \times 10^{7}$ cells $\mathrm{mL}^{-1}$ (adjusted by a direct microscopic count using a Neubauer's Chamber) that had been previously cultivated in YMM medium with or without the addition of 1 ammonium sulfate $1 \%$. Later, the fruits were stored in plastic boxes wrapped with high density polythene $(\mathrm{H} \times \mathrm{W} \times \mathrm{D}=14 \times 30 \times 36.5 \mathrm{~cm})$ and incubated at $25^{\circ} \mathrm{C}$ and $10 \pm 3{ }^{\circ} \mathrm{C}$ and $90 \pm 3 \% \mathrm{RH}$.

The yeast population was monitored every 2 days until 16 days of storage at $25^{\circ} \mathrm{C}$ and every 5 days until 30 days of storage at $10^{\circ} \mathrm{C}$. The entire wound was excised from the fruit with a cork borer $(0.5 \mathrm{~cm}$ diameter), placed in $10 \mathrm{~mL}$ sterile $0.05 \mathrm{M}$ potassium phosphate buffer at pH 7.0, and ground thoroughly with a mortar and pestle. Tenfold serial dilutions of the slurry were made, and $100 \mu \mathrm{L}$ of each dilution was spread onto PDA medium (with the addition of $0.1 \mathrm{~g}$ of ampicillin and $0.1 \mathrm{~g}$ of nalidixic acid/L). The cultures were incubated at $25^{\circ} \mathrm{C}$ for $72 \mathrm{~h}$ before the colony counts were conducted. The population densities of A. pullulans are expressed as $\log _{10} \mathrm{CFU} /$ wound. The individual fruit wound served as one replicate in a randomized complete block design, and 5 replicates were sampled at each sampling time (this protocol was adapted from Luo et al., 2012).

\subsection{Electron microscopy study of the interaction between Geotrichum citri-aurantii and Aureobasidium pullulans at the infection site}

Surface colonization and attachment of $A$. pullulans at wound sites were examined according to Mekbib et al. (2011). Commercially mature Pera orange fruits were washed with mild detergent, the surface was disinfected with Dioxiplus ${ }^{\circledR}(2 \mathrm{~mL} / \mathrm{L})$, and they were injured with sterile needles to a depth of $3 \mathrm{~mm}$. The wounds were treated with $30 \mu \mathrm{L}$ of a suspension of $A$. pullulans $\left(1 \times 10^{7}\right.$ cells $\mathrm{mL}^{-1}$ ) after cultivation on YMM medium with or without the 
addition of ammonium sulfate $1 \%$ at $25{ }^{\circ} \mathrm{C}$ and $150 \mathrm{rpm}$ for $96 \mathrm{~h}$. Inoculation of the phytopathogen occurred $24 \mathrm{~h}$ after the treatment with yeast using a $30 \mu \mathrm{L}$ suspension of the fungus $\left(1 \times 10^{5}\right.$ conidia $\left.\mathrm{mL}^{-1}\right)$. The control fruits were treated with sterile distilled water instead of another treatment. The fruits were stored in plastic boxes wrapped with high density polythene and incubated at $25{ }^{\circ} \mathrm{C}$ and $10 \pm 3{ }^{\circ} \mathrm{C}$ and $90 \pm 3 \% \mathrm{RH}$.

The samples were taken 48 and $72 \mathrm{~h}$ after inoculation. To this end, the entire wound was excised from the fruit with a cork borer $(0.5 \mathrm{~cm}$ diameter) and immersed in glutaraldehyde (2.5\%) in $0.1 \mathrm{M}$ phosphate buffer at $\mathrm{pH} 7.3$ for $24 \mathrm{~h}$. The samples were washed 5 times over $1 \mathrm{~h}$ with distilled water, immersed in $0.5 \%$ osmium tetroxide and dehydrated in a series of ethanol concentrations before critical point drying. The dried tissues were mounted on aluminium stubs coated with gold-palladium, and electron micrographs were produced using a Quanta 200 scanning electron microscope (FEI Company) operating at $6 \mathrm{kV}$.

\subsection{Statistical analysis}

The data were analysed by ANOVA, and the mean values were compared with Tukey's test at the 5\% significance level using the ASSISTAT 7.6 software package. All experiments were repeated twice.

\section{Results}

\subsection{Effect of nutrient sources on the antagonistic activity of Aureobasidium pullulans}

The data from the addition of sources of nitrogen and micronutrients to the culture medium to increase the antagonistic activity of $A$. pullulans on the mycelial growth of $G$. citri-aurantii showed that the micronutrients were more efficient in facilitating the antagonistic action of yeast. The addition of nutrients in the cultivation of yeast, including cobalt chloride, ammonium molybdate and boric acid at a concentration of $1 \mathrm{mM}$, showed the best results, with inhibition percentages of G. citri-aurantii colonies of 77,80 and $100 \%$, respectively, compared with the control, which was constituted of the fungus grown without micronutrients (Table 1).

None of the nutrients tested affected the mycelial growth of G. citri-aurantii when tested on the pathogen directly (without yeast), demonstrating that these nutrients have no antifungal effect on the pathogen. The mixture of the best nutrients was not found to favour the antagonism of ACBL-77 (data not shown).

\subsection{Effect of different sources of nutrients on the competition between Aureobasidium pullulans and Geotrichum citri-aurantii}

The results of the study of competition for nutrients on the interactions between A. pullulans ACBL-77 and G. citri-aurantii evaluated by spore germination of the pathogen are displayed in Table 2. The addition of nutrients in treatments such as ACBL $-77+$ ammonium sulfate $1 \%$, ACBL-77 + boric acid $1 \mathrm{mM}$, ACBL77 + sucrose $0.5 \%$ and ACBL-77 + cobalt chloride $1 \mathrm{mM}$, promoted the inhibition of the spore germination of the phytopathogen at percentages of $92,89,87$ and $86 \%$, respectively. These values are higher than those found when the yeast was used without nutrients (71\% inhibition of germination). The control treatment (pathogen + nutrients and without yeast) showed an increase in the germination of conidia of G. citri-aurantii.

\subsection{Effect of nutrient sources in the culture medium on the production of cells by Aureobasidium pullulans}

The data for the effect of nutrients on the production of cells by A. pullulans are reported in Fig. 1. According to the previous results, five different nutrients were chosen for this study: ammonium sulfate $1 \%$; sucrose $0.5 \%$; boric acid $1 \mathrm{mM}$; cobalt chloride $1 \mathrm{mM}$ and ammonium molybdate $1 \mathrm{mM}$. The direct effects of these nutrients on cell production by $A$. pullulans ACBL-77 were evaluated using YMM medium with or without these nutrients over different incubation periods.

The yeast cultivated with the addition of ammonium sulfate $1 \%$ showed a higher peak production of colony forming units $\left(1.43 \times 10^{7} \mathrm{CFU} \mathrm{mL} \mathrm{m}^{-1}\right)$ by approximately $48 \mathrm{~h}$ of incubation. The peak cell production of $A$. pullulans grown without any other nutrients was observed at the same time; however, the addition of ammonium sulfate $1 \%$ resulted in the same concentration of viable cells up to $144 \mathrm{~h}$ of incubation. In the control treatment (without nutrients), the decline phase was much faster. With the addition of sucrose $0.5 \%$ to the medium, $96 \mathrm{~h}$ of incubation was sufficient for most yeast growth, but the decline phase in this treatment was faster, as well. The nutrients cobalt chloride and/or ammonium molybdate $(1 \mathrm{mM})$ do not allow the growth of ACBL-77, so that during the first $48 \mathrm{~h}$ the yeast remains in the lag phase. After this time, the decline phase starts.

\subsection{Biofilm formation}

The study of the interference of the addition of nutrients in the yeast culture in terms of the quantification of biofilm formation by A. pullulans showed a significant increase in biofilm formation with the addition of ammonium sulfate $1 \%$ compared with the yeast cultivated without other nutrients. When cobalt chloride or ammonium molybdate, both at a concentration of $1 \mathrm{mM}$, was added to the medium, inhibition to biofilm formation by the strain ACBL77 occurred (Fig. 2).

Except for the treatment with ammonium sulfate 1\%, the pathogen's presence in the cultivation of yeast caused a reduction in biofilm formation by the antagonist (Fig. 3).

\subsection{Antifungal activity of Aureobasidium pullulans in vivo}

The efficacies of different nutrients added to yeast cultures in reducing sour rot are reported in Figs. 4 and 5. In detail, the fruits treated with A. pullulans ACBL-77 cultured in YMM without other nutrients showed 65 and 85\% curative and preventive control, respectively. When the yeast was cultivated in YMM with ammonium sulfate $1 \%$ added, the control rates were significantly higher, showing $82-100 \%$ curative and preventive control, respectively.

The treatments with the other nutrients and chemical control (Thiabendazole ${ }^{\mathbb{R}}$ ) did not show efficiency in the control of sour rot of citrus fruits, showing results that were equal to those of the control (untreated fruits).

\subsection{Colonization of citrus wound by Aureobasidium pullulans}

The population dynamics of $A$. pullulans ACBL-77 on artificially wounded citrus fruits are displayed in Fig. 6. The yeast was able to quickly colonize citrus wounds under the two storage conditions $\left(25\right.$ and $10^{\circ} \mathrm{C}$ ). The concentration of yeast cells increased tenfold compared to the initial inoculum $\left(1 \times 10^{6} \mathrm{CFU}\right.$ wound $\left.{ }^{-1}\right)$ after two days of incubation and gradually became stable (stationary phase) between 8 and 10 days under both storage temperatures. After this 
Table 1

Effect of nitrogen sources and micronutrients on Aureobasidium pullulans strain ACBL-77 antagonistic activity on the mycelial growth of Geotrichum citri-aurantii.

\begin{tabular}{|c|c|c|}
\hline Treatments & Colony size $(\mathrm{cm})$ of $G$. citri-aurantii & $\%$ Inhibition \\
\hline Urea $0.02 \%$ & $6.75 \mathrm{~b}^{\mathrm{a}}$ & 18.67 \\
\hline Urea $0.1 \%$ & $6.87 \mathrm{~b}$ & 17.22 \\
\hline Urea $0.5 \%$ & $7.95 \mathrm{a}$ & 4.21 \\
\hline Ammonium sulfate $0.02 \%$ & $5.92 \mathrm{c}$ & 28.67 \\
\hline Ammonium sulfate $0.1 \%$ & $4.45 \mathrm{e}$ & 46.38 \\
\hline Ammonium sulfate $0.5 \%$ & $3.92 \mathrm{f}$ & 52.77 \\
\hline Ammonium nitrate $0.02 \%$ & $7.00 \mathrm{~b}$ & 15.76 \\
\hline Ammonium nitrate $0.1 \%$ & $5.45 \mathrm{~d}$ & 34.33 \\
\hline Ammonium nitrate $0.5 \%$ & $6.42 \mathrm{~b}$ & 22.65 \\
\hline Tryptone $0.02 \%$ & $6.77 \mathrm{~b}$ & 18.43 \\
\hline Tryptone $0.1 \%$ & $7.07 \mathrm{~b}$ & 14.81 \\
\hline Tryptone $0.5 \%$ & $5.45 \mathrm{~d}$ & 34.33 \\
\hline Potassium nitrate $0.02 \%$ & $7.00 \mathrm{~b}$ & 15.76 \\
\hline Potassium nitrate $0.1 \%$ & $6.57 \mathrm{~b}$ & 20.84 \\
\hline Potassium nitrate $0.5 \%$ & $7.12 \mathrm{a}$ & 14.21 \\
\hline Boric acid $0.05 \mathrm{mM}$ & $5.22 \mathrm{~d}$ & 37.10 \\
\hline Boric acid $0.2 \mathrm{mM}$ & $3.17 \mathrm{~g}$ & 61.80 \\
\hline Boric acid $1 \mathrm{mM}$ & $0 \mathrm{i}$ & 100 \\
\hline Copper sulfate $0.05 \mathrm{mM}$ & $6.00 \mathrm{c}$ & 27.71 \\
\hline Copper sulfate $0.2 \mathrm{mM}$ & $6.82 \mathrm{~b}$ & 17.83 \\
\hline Copper sulfate $1 \mathrm{mM}$ & $4.65 \mathrm{e}$ & 43.97 \\
\hline Zinc sulfate $0.05 \mathrm{mM}$ & $6.17 \mathrm{c}$ & 25.66 \\
\hline Zinc sulfate $0.2 \mathrm{mM}$ & $6.67 \mathrm{~b}$ & 19.63 \\
\hline Zinc sulfate $1 \mathrm{mM}$ & $5.32 \mathrm{~d}$ & 35.90 \\
\hline Manganese sulfate $0.05 \mathrm{mM}$ & $6.20 \mathrm{c}$ & 25.30 \\
\hline Manganese sulfate $0.2 \mathrm{mM}$ & $6.20 \mathrm{c}$ & 25.30 \\
\hline Manganese sulfate $1 \mathrm{mM}$ & $6.00 \mathrm{c}$ & 27.71 \\
\hline Cobalt chloride $0.05 \mathrm{mM}$ & $5.57 \mathrm{~d}$ & 32.89 \\
\hline Cobalt chloride $0.2 \mathrm{mM}$ & $6.52 \mathrm{~b}$ & 21.44 \\
\hline Cobalt chloride $1 \mathrm{mM}$ & $1.87 \mathrm{~h}$ & 77.46 \\
\hline Ferric chloride $0.05 \mathrm{mM}$ & $6.97 \mathrm{~b}$ & 16.02 \\
\hline Ferric chloride $0.2 \mathrm{mM}$ & $6.10 \mathrm{c}$ & 26.50 \\
\hline Ferric chloride $1 \mathrm{mM}$ & $5.10 \mathrm{~d}$ & 38.55 \\
\hline Ammonium molybdate $0.05 \mathrm{mM}$ & $6.25 \mathrm{c}$ & 24.69 \\
\hline Ammonium molybdate $0.2 \mathrm{mM}$ & $5.55 \mathrm{~d}$ & 33.13 \\
\hline Ammonium molybdate $1 \mathrm{mM}$ & $1.67 \mathrm{~h}$ & 79.87 \\
\hline ACBL-77 (without nutrients) & $5.82 \mathrm{c}$ & 29.87 \\
\hline Control (only G. citri-aurantii) & $8.30 \mathrm{a}$ & - \\
\hline
\end{tabular}

a Means followed by the same lowercase letter are not significantly different according to Tukey's test $(\mathrm{P}<0.05)$.

period, the yeast cell production was $4.42 \log { }^{10} \mathrm{CFU}$ wound ${ }^{-1}$ on the 14th $\left(25^{\circ} \mathrm{C}\right)$ and 20 th days of storage $\left(10^{\circ} \mathrm{C}\right)$. At the end of the evaluations, the concentration of yeast cells decreased to $3.35 \mathrm{log}$ ${ }^{10} \mathrm{CFU}$ wound ${ }^{-1}$ and $3.25 \log { }^{10} \mathrm{CFU}$ wound ${ }^{-1}$ under the storage conditions of $25{ }^{\circ} \mathrm{C}$ and $10{ }^{\circ} \mathrm{C}$, respectively. These decreases were lower when the yeast was cultivated with ammonium sulfate $1 \%$, with the antagonist cell concentrations dropping to $4.65 \log { }^{10} \mathrm{CFU}$ wound $^{-1}$ and $4.42 \log { }^{10} \mathrm{CFU}$ wound $^{-1}$ under the fruit storage conditions of $25^{\circ} \mathrm{C}$ and $10^{\circ} \mathrm{C}$, respectively.

\subsection{Electron microscopy study of the interaction between Geotrichum citri-aurantii and Aureobasidium pullulans at the infection site}

The development of $G$. citri-aurantii in citrus wounds previously treated with A. pullulans cultured in YMM with or without the addition of ammonium sulfate $1 \%$ was assessed by observation under a scanning electron microscope 48 and $72 \mathrm{~h}$ after inoculation with the pathogen, as reported in Fig. 7. For the two sampling times, deformation and swelling in the hyphae of the pathogen was observed in the two treatments when compared to the control (G. citri-aurantii, untreated).

The treatments with the strain ACBL-77 caused damage to the pathogen hyphae (Fig. 7A-B). However, when the yeast was cultured in the medium with added ammonium sulfate $1 \%$, the accumulation of extracellular matrix and the clustering of cells around the wound and therefore around the hyphae was observed, mainly in the sample taken $72 \mathrm{~h}$ after inoculation with G. citriaurantii (Fig. 7C-D). In the control treatment, the conidia and hyphae showed no deformation (Fig. 7 E).

\section{Discussion}

The use of yeast antagonists to control postharvest diseases is a promising technology for the complete or partial reduction of chemicals commonly used during the processing of fruit in packing houses. The main mechanisms of action attributed to these microorganisms include the competition for space and nutrients, biofilm formation and the production of hydrolytic enzymes, which favour biocontrol during the postharvest period (Liu et al., 2013; Parafati et al., 2015; Spadaro and Droby, 2016). The antagonistic interactions between A. pullulans strain ACBL-77 and G. citri-aurantii were studied by varying the sources of nutrients in the yeast culture medium.

The micronutrients cobalt chloride, ammonium molybdate and boric acid (all at $1 \mathrm{mM}$ ) were efficient, enhancing the antagonistic action of the yeast and decreasing the mycelial growth of the pathogen (Table 1). According to Conrad et al. (2014), each micronutrient has specific mechanisms in regulating cell growth, which can interfere with protein synthesis in each microorganism and cause changes in their enzymatic pathways and the regulation of the expression of ribosomal genes. Accordingly, this interference 
Table 2

Competition for nutrients between Aureobasidium pullulans and Geotrichum citri-aurantii.

\begin{tabular}{|c|c|c|}
\hline Treatments & $\%$ conidial germination & $\%$ inhibition conidial germination \\
\hline ACBL-77 (without nutrients) & $28.83 \mathrm{~g}^{\mathrm{a}}$ & 71.28 \\
\hline Ammonium sulfate $0.5 \%$ & $96.66 \mathrm{a}$ & 3.34 \\
\hline Ammonium sulfate $1 \%$ & $98.66 \mathrm{a}$ & 1.40 \\
\hline ACBL-77 + Ammonium sulfate $0.5 \%$ & $15.66 \mathrm{i}$ & 84.34 \\
\hline ACBL-77 + Ammonium sulfate $1 \%$ & $8.33 \mathrm{j}$ & 91.67 \\
\hline Phenylalanine $0.5 \%$ & $97.50 \mathrm{a}$ & 2.50 \\
\hline Phenylalanine $1 \%$ & $96.83 \mathrm{a}$ & 3.17 \\
\hline ACBL-77 + Phenylalanine $0.5 \%$ & $19.66 \mathrm{~h}$ & 80.34 \\
\hline ACBL-77 + Phenylalanine 1\% & $11.33 \mathrm{j}$ & 88.67 \\
\hline Leucine $0.5 \%$ & $93.66 \mathrm{a}$ & 6.34 \\
\hline Leucine $1 \%$ & $89.00 \mathrm{~b}$ & 11.00 \\
\hline ACBL-77 + Leucine $0.5 \%$ & $24.50 \mathrm{~g}$ & 75.50 \\
\hline ACBL-77 + Leucine $1 \%$ & $17.50 \mathrm{i}$ & 82.50 \\
\hline Proline $0.5 \%$ & $98.66 \mathrm{a}$ & 1.34 \\
\hline Proline $1 \%$ & $97.00 \mathrm{a}$ & 3.00 \\
\hline ACBL-77 + Proline $0.5 \%$ & $23.50 \mathrm{~g}$ & 76.50 \\
\hline ACBL-77 + Proline $1 \%$ & $44.33 \mathrm{e}$ & 55.67 \\
\hline Sucrose $0.5 \%$ & $94.50 \mathrm{a}$ & 5.50 \\
\hline Sucrose $1 \%$ & $95.83 \mathrm{a}$ & 4.17 \\
\hline ACBL-77 + Sucrose $0.5 \%$ & $12.66 \mathrm{j}$ & 87.34 \\
\hline ACBL-77 + Sucrose $1 \%$ & $42.83 \mathrm{e}$ & 57.17 \\
\hline Maltose $0.5 \%$ & $98.16 \mathrm{a}$ & 1.84 \\
\hline Maltose $1 \%$ & $98.33 \mathrm{a}$ & 1.67 \\
\hline ACBL-77 + Maltose $0.5 \%$ & $24.50 \mathrm{~g}$ & 75.50 \\
\hline ACBL-77 + Maltose 1\% & $38.66 \mathrm{f}$ & 61.34 \\
\hline Galactose $0.5 \%$ & $95.83 \mathrm{a}$ & 4.17 \\
\hline Galactose $1 \%$ & $95.66 \mathrm{a}$ & 4.34 \\
\hline ACBL-77 + Galactose $0.5 \%$ & $22.50 \mathrm{~g}$ & 77.50 \\
\hline ACBL-77 + Galactose 1\% & $26.50 \mathrm{~g}$ & 73.50 \\
\hline Fructose $0.5 \%$ & $95.33 \mathrm{a}$ & 4.67 \\
\hline Fructose $1 \%$ & $96.50 \mathrm{a}$ & 3.50 \\
\hline ACBL-77 + Fructose $0.5 \%$ & $18.50 \mathrm{~h}$ & 81.50 \\
\hline ACBL-77 + Fructose $1 \%$ & $19.16 \mathrm{~h}$ & 80.84 \\
\hline Boric acid $1 \mathrm{mM}$ & $81.50 \mathrm{c}$ & 18.50 \\
\hline ACBL-77 + Boric acid $1 \mathrm{mM}$ & $11.33 \mathrm{j}$ & 88.67 \\
\hline Cobalt chloride $1 \mathrm{mM}$ & $66.66 \mathrm{~d}$ & 33.34 \\
\hline ACBL-77 + Cobalt chloride $1 \mathrm{mM}$ & $13.83 \mathrm{i}$ & 86.17 \\
\hline Ammonium molybdate $1 \mathrm{mM}$ & $99.00 \mathrm{a}$ & 1.00 \\
\hline ACBL-77 + Ammonium molybdate & $39.83 \mathrm{f}$ & 60.17 \\
\hline Control (only G. citri-aurantii) & $69.00 \mathrm{~d}$ & 31.00 \\
\hline
\end{tabular}

${ }^{a}$ Means followed by the same lowercase letter are not significantly different according to Tukey's test $(\mathrm{P}<0.05)$.
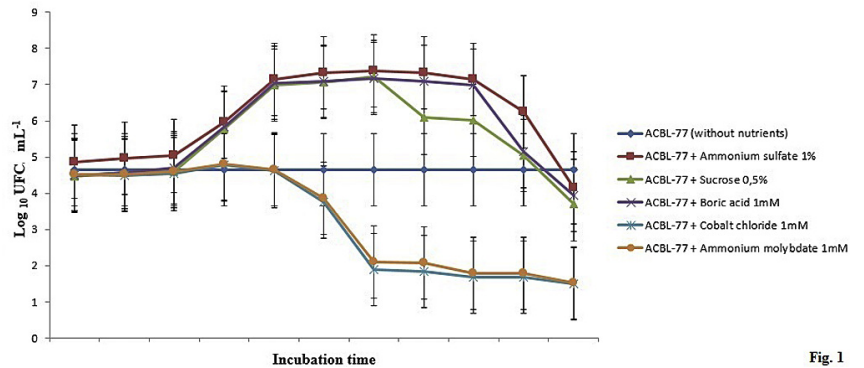

Fig. 1. Viable cell production by Aureobasidium pullulans strain ACBL-77 cultivated in YMM medium with different sources of nutrients over different incubation periods. Error bars indicate standard deviations $( \pm \mathrm{SD})$ of four replications.

may affect the performance of the antagonist both positively and negatively, for example in the production of some metabolites. In this study, the micronutrients added to the yeast culture were observed to favour the antagonistic activity of A. pullulans, inhibiting the development of G. citri-aurantii.

In the study of competition for nutrients between the yeast and the phytopathogen, in addition to the micronutrients, ammonium sulfate $1 \%$ and sucrose $0.5 \%$ caused an increase in the percentage of inhibition of conidial germination compared with that observed for the yeast growing without nutrients (Table 2). Studies in vitro and

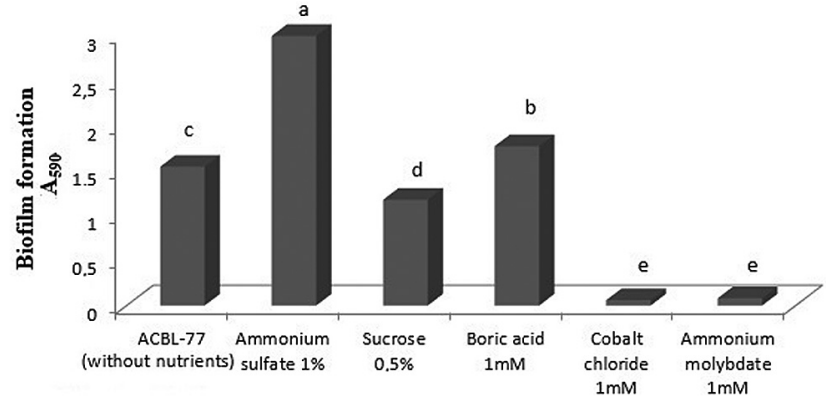

Fig. 2. Biofilm formation by Aureobasidium pullulans strain ACBL-77 cultivated in YMM medium with different nutrients. Control indicates yeast cells grown without any nutrients. The data represent the mean of six replicates. Means followed by the same letter do not differ statistically by Tukey's test ( $\mathrm{p} \geq 0.05$ ).

in vivo on the competition for nutrients between $A$. pullulans and Penicillium expansum on apples conducted by Bencheqroun et al. (2007) showed a reduction in the pathogen spore germination and thus the competition for amino acids between these microorganisms. Furthermore, the authors observed a reduction in the severity of the disease, with a reduction in the size of lesions by up to $97 \%$. Mari et al. (2012) related that A. pullulans were efficient in the biological control of Colletotrichum acutatum (bitter rot) and 


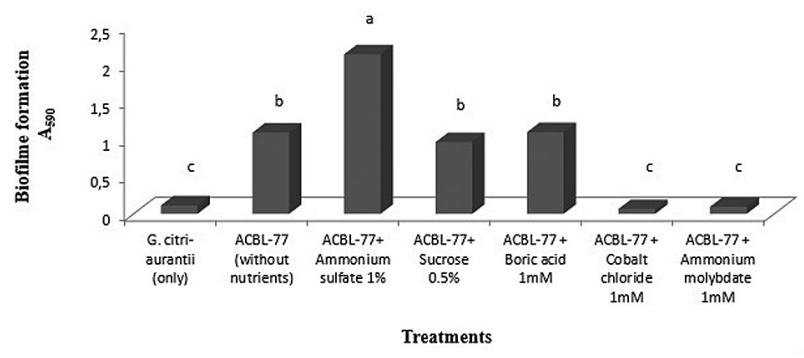

Fig. 3. Biofilm formation by Aureobasidium pullulans strain ACBL-77 cultivated with different nutrients in YMM medium with or not the presence of Geotrichum citriaurantii. The data represent the mean of six replicates. Means followed by the same letter do not differ statistically by Tukey's test ( $\mathrm{p} \geq 0.05$ ).

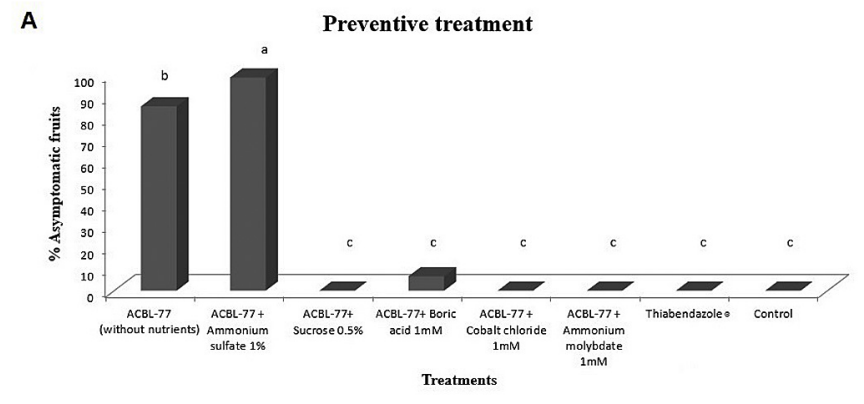

B

Curative treatment

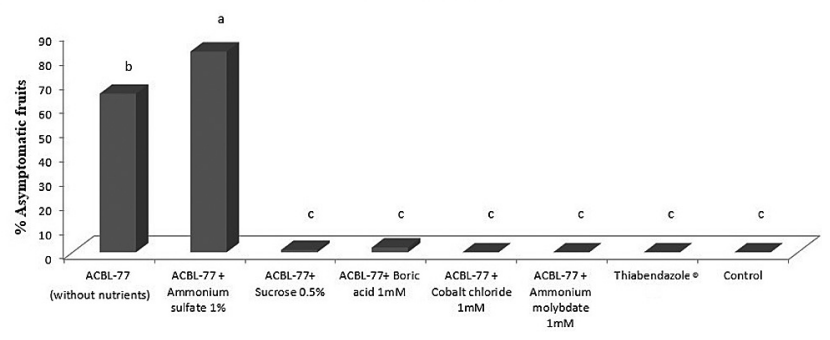

Fig. 4. In vivo antagonistic activity of Aureobasidium pullulans strain ACBL-77 $\left(1 \times 10^{7}\right.$ cells $\left.\mathrm{mL}^{-1}\right)$ cultivated in YMM medium with or without the addition of nutrients for the biocontrol of Geotrichum citri-aurantii $\left(1 \times 10^{5}\right.$ conidia $\left.\mathrm{mL}^{-1}\right)$ on Pera orange fruits. A - Preventive treatment; B - Curative treatment. The fruits were incubated at $25 \pm 3{ }^{\circ} \mathrm{C}$ and $90 \pm 3 \%$ relative humidity for 15 days. Means followed by the same letter do not differ statistically by Tukey's test ( $\mathrm{p} \geq 0.05$ ).

P. expansum (blue mould) and specially Botrytis cinerea, with total control of grey mould in apple fruit. Already Liu et al. (2010) reported that applications of cell suspension of Cryptococcus laurentii in citrus fruits reduced the sour rot incidence approximately $55 \%$.

The growth curves of $A$. pullulans strain ACBL-77 showed that the stages of development of the yeast were influenced by the nutrient sources used in the culture medium. In this work the addition of ammonium sulfate $1 \%$ to the medium promoted a greater production of active colonies at $48 \mathrm{~h}$; and the stationary phase was extended to up to $144 \mathrm{~h}$ of incubation (Fig. 1). Our results are similar with those reported by Ouedraogo et al. (2017), according to these authors, the supplementation of medium with nitrogen source enhanced the Candida utilis biomass production.

The biofilm production of $A$. pullulans occurs in the stationary phase (Ravella et al., 2010), and an increase in this stage, depending on the nutrient, also allowed an increase in the production of biofilm (Fig. 2). Our results are in accordance with data reported by Yurlova and Hoog (1997), showing that EPSs can be stimulated by the concentration of different nitrogen sources during the culture of microorganisms. Ravella et al. (2010) and Bulmer et al. (1987)

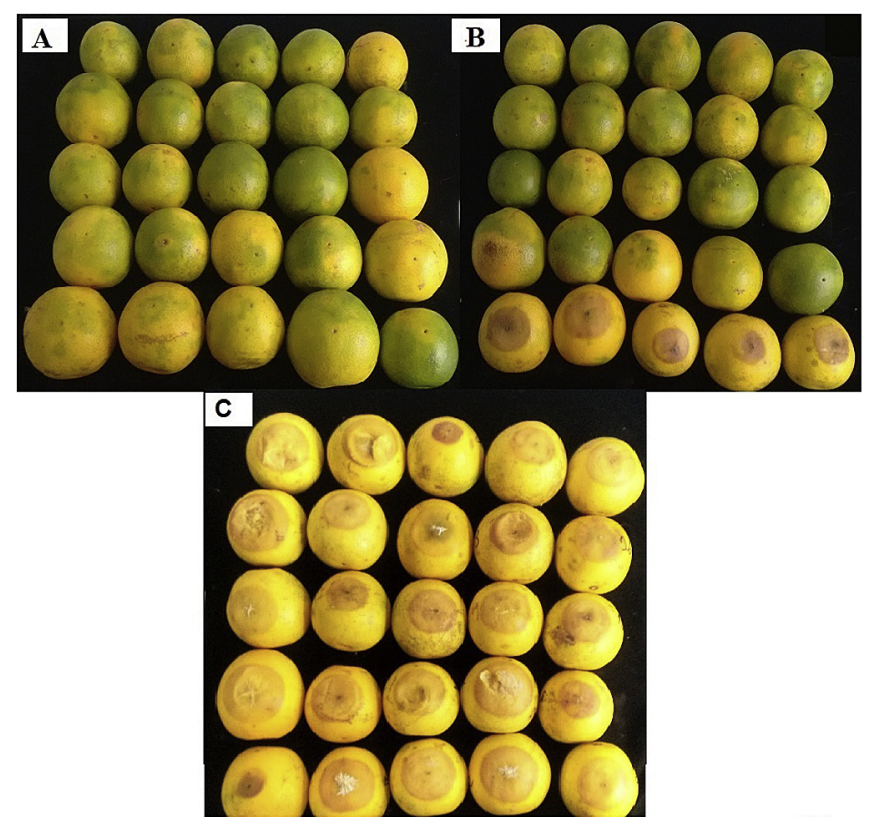

Fig. 5. Pera orange inoculated with Geotrichum citri-aurantii $\left(1 \times 10^{5}\right.$ conidia $\left.\mathrm{mL}^{-1}\right)$ and treated preventively with a suspension of $A$. pullulans $\left(1 \times 10^{7}\right.$ cells $\left.\mathrm{mL}^{-1}\right)$ : A ACBL-77 grown on YMM medium plus ammonium sulfate 1\%; B - ACBL-77 grown on YMM medium; $\mathrm{C}-$ untreated fruits. The fruits were incubated at $25 \pm 3{ }^{\circ} \mathrm{C}$ and $90 \pm 3 \%$ relative humidity for 15 days.
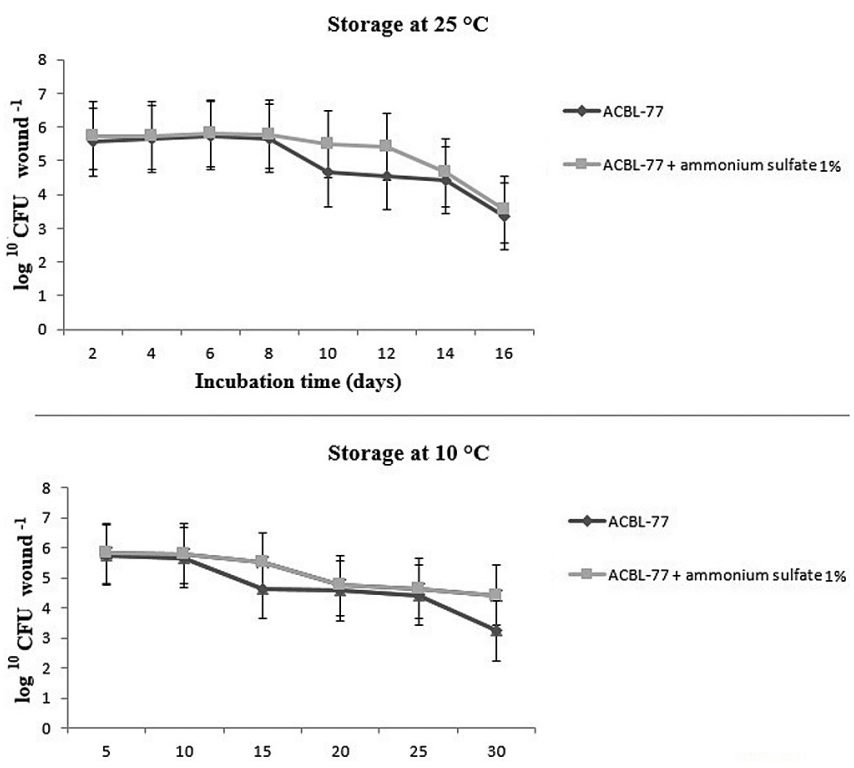

Fig. 6. Population dynamics of Aureobasidium pullulans strain ACBL-77 cultured on YMM medium with or without ammonium sulfate $1 \%$ and applied to citrus fruit wounds and stored at $\mathrm{A}-$ incubated at $25^{\circ} \mathrm{C}$ for 16 days, and $\mathrm{B}-$ incubated at $10{ }^{\circ} \mathrm{C}$ for 30 days. The fruits were incubated at $90 \pm 3 \%$ relative humidity. Each point represents the mean of five replicates. Error bars indicate standard deviations $( \pm S D)$ of five replications.

found increased pullulan production with the addition of ammonium sulfate and ammonium nitrate in the medium used to cultivate $A$. pullulans, respectively. On the other hand, our data are not consistent with those published by Parafati et al. (2015), in which the authors demonstrated that $A$. pullulans showed high wound colonization capacity in grapes but no biofilm formation in vitro.

According to Droby et al. (2009), biofilm formation is a process 

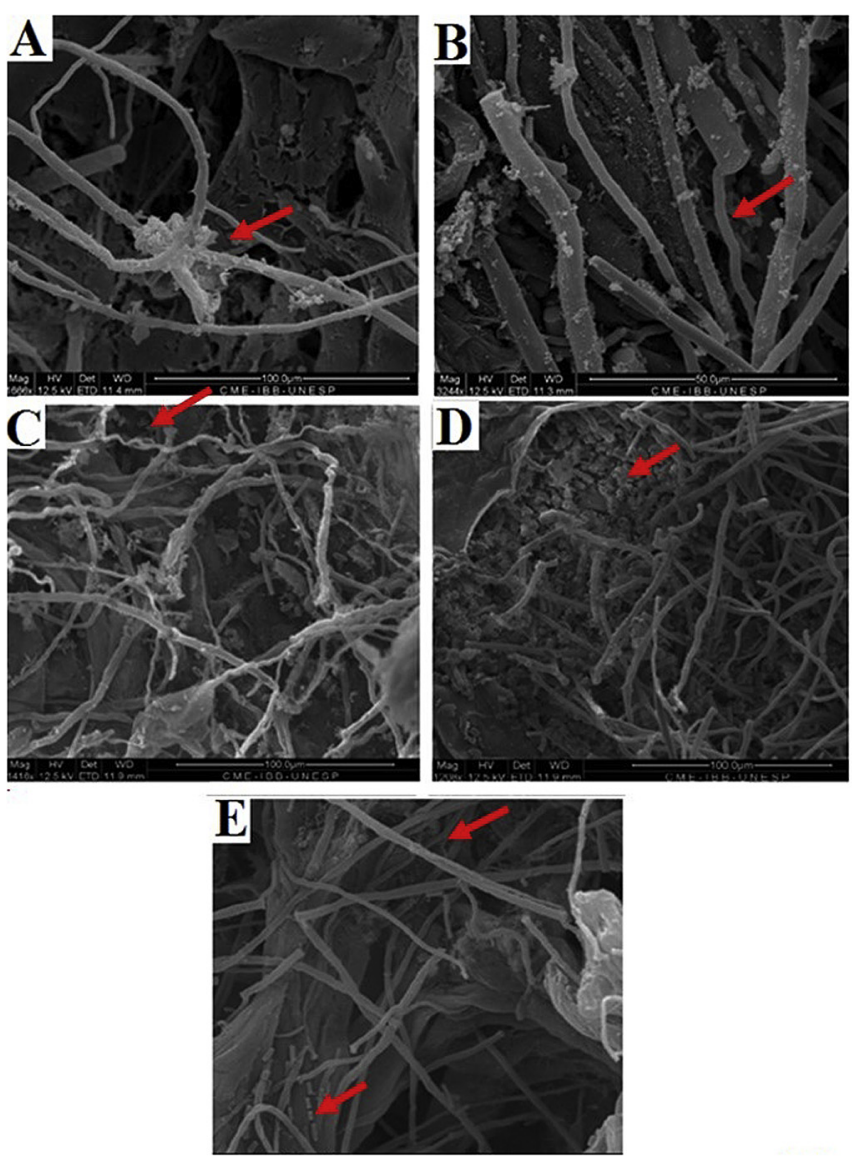

Fig. 7. Scanning electron micrographs of wound sites on orange fruits treated with Aureobasidium pullulans strain ACBL-77 and inoculated with Geotrichum citri-aurantii. The sequence of micrographs in each photo was taken after 48 and $72 \mathrm{~h}$ of incubation time at $25{ }^{\circ} \mathrm{C}$, respectively. A-B - ACBL-77 cultivated in YMM medium; C-D - ACBL-77 cultivated in YMM medium plus $1 \%$ ammonium sulfate; $\mathrm{E}$ - untreated fruit. The arrows indicate: A) possible mycoparasitism; B and C) deformation in the pathogen hyphae; D) accumulation of ACBL-77 cells around the wound and hyphae; E) Normal hyphae and conidia.

in which microorganisms form multicellular structures embedded in a complex matrix that allows them to better adhere to surfaces, increasing their resistance to stresses. Therefore, biofilm formation may be considered an important feature for postharvest biocontrol agents during the colonization of the substrate and fruit wounds.

Thus, under in vivo conditions, the applications of yeast (without nutrient) were efficient, but when the ACBL-77 grown in media containing ammonium sulfate $1 \%$ showed the best control when the incidence of sour rot was evaluated (Figs. 4 and 5). These results indicate that the increase in biofilm may have improved biocontrol. According to Spadaro (2014), biofilm formation capacity in surface wounds is a strong biocontrol mechanism of antagonistic microorganisms. Scherm et al. (2003) reported that only cells collected from the biofilm phase of Saccharomyces cerevisiae isolate were effective in the control of $P$. expansum in apple fruit. Vero et al. (2013) associated the antagonistic activity of Leucosporidium scottii against $P$. expansum and $B$. cinerea in apples by the biofilm produced from the antagonistic. According to Pu et al. (2014), Kloeckera apiculate, an isolate able to embed in an extracellular matrix and produce biofilm on citrus fruit showed greater biocontrol ability against Penicillium italicum. Chi et al. (2015) related that the biofilm production by Pichia kudriavzevii improved the biocontrol of B. cinerea and Colletotrichum gloeosporioides on pear fruits. Furthermore, according to Li et al. (2015) the morphology transition from a single-cell to a pseudohyphal/biofilm of the yeast Candida diversa improves the biocontrol of $B$. cinerea in apple and kiwifruit.

Regarding the importance of studies on various nutrient sources used in combination with antagonistic yeasts, Droby et al. (2003) used various salts (sodium bicarbonate, calcium propionate and sodium ethylenediaminetetraacetic acid) in combination with the Aspire $^{\circledR}$ bioproduct (Candida oleophila based-formulation), showing that the nutrients exhibited the ability to significantly improve biocontrol against $B$. cinerea and $P$. expansum in apple and Monilinia fructicola and Rhizopus stolonifer in peach.

The rapid growth and high population density of antagonistic microorganisms in fruit wounds are advantages allowing them to compete with pathogens for nutrients and space and are considered important modes of action in many biological control systems during the postharvest period (Liu et al., 2013). The rapid multiplication of $A$. pullulans in citrus fruit wounds indicated that this strain colonizes and establishes in fruit wounds, thereby allowing it to function as a biocontrol agent. In this work addressing the population dynamics of $A$. pullulans in orange fruits, yeast previously grown in media supplemented with a source of nitrogen (ammonium sulfate 1\%) ensured better stability for their cell viability, allowing the greater production of colony-forming units of yeast for a longer period of time (Fig. 6).

One hypothesis for the success of the incorporation of ammonium sulfate into the yeast culture medium is that ammonium ions are transported by an energy-dependent system (ATP). This transport system appears to be the reason for the acceleration of yeast respiration and fermentation. The effects of the ammonium ion on the phosphofructokinase reaction cannot be overlooked; however, the concentration of this ion in the cell may have an effect on enzymes related to nitrogen metabolism, such as glutamate-ammonia ligase. Another reason for the acceleration of metabolism could be the increased efficiency of biosynthetic pathways (Nielsen, 1997). Furthermore, according to Broach (2012), the addition of ammonium to the yeast cell culture may change transcription, including the induction of genes required for the growth of the microorganism.

In fact, the use of ammonium sulfate $1 \%$ improves the antagonist action of the A. pullulans strain ACBL-77, as demonstrated in the in vivo assays, most likely because this nitrogen source increased biofilm production. The biofilm possibly optimizes yeast survival on wounded citrus during the storage of the fruit.

The scanning electron microscopy observations indicated that the treatment with A. pullulans ACBL-77 caused damages to the pathogen hyphae. It is verified that the yeast cultured into medium with addition of ammonium sulfate $(1 \%)$ and applied on wounded fruits, there was accumulation of extracellular matrix and agglomeration of yeast cells around the wound and, therefore, around the hyphae. Furthermore, probably, the addition of this nitrogen source facilitated the rapid colonization of yeast in fruit wounds, which may explain the better results found when applying ACBL-77, cultivated previously in medium with addition of ammonium sulfate (1\%), favouring survival of yeast in citrus fruits. Lima et al. (2013) described about colonization and adhesion of yeasts Wickerhamomyces anomalus and Meyerozyma guilliermondii on hyphae of Colletotrichum gloeosporioides, after studies in electron microscopy, confirming the occurrence of mycoparasitism of the antagonists. In addition, extracellular matrices of antagonistic yeasts can lyse the fungal hyphae, increasing the source of available nutrients, such as carbon, which can be used by the biological control agent (Zhang et al., 2010).

\section{Conclusions}

These results show the importance of the addition of nutrients 
and the types of nutrients used in future A. pullulans basedformulations for use on a commercial scale. Moreover, this is the first report of a positive correlation between an increase in the quantity of biofilm produced by yeast depending on the nutrient added to culture medium and a consequent increase in its antagonistic activity against $G$. citri-aurantii.

This informations should be taken into account for further studies, particularly when deciding formulation. Furthermore, more studies should be performance about others substances produced by A. pullulans ACBL-77 that be related to the biocontrol of $G$. citri-aurantii with biotechnological potential.

\section{Acknowledgements}

The financial support of CAPES, which provided a scholarship to Mariana N. Klein, is gratefully acknowledged. We also thank the Citricola Lucato for the citrus fruits donated.

\section{References}

Adikaram, N.K.B., Joyce, D.C., Terry, L.A., 2002. Biocontrol activity and induced resistance as a possible mode of action for Aureobasidium pullulans against grey mould of strawberry fruit. Australas. Plant Pathol. 31, 223-229.

Bencheqroun, S.K., Bajji, M., Massart, S., Labhilili, M., Jaafari, S., Jijakli, M.H., 2007. In vitro and in situ study of postharvest apple blue mold biocontrol by Aureobasidium pullulans: evidence for the involvement of competition for nutrients. Postharvest Biol. Technol. 46, 128-135.

Brazil, Oct. 7, 2014. Ministry of Labor and Employment. Portaria Interministerial $n^{\circ}$ 9.

Broach, J.R., 2012. Nutritional control of growth and development in yeast. Genetics 192, 73-105.

Brown, G.E., 1988. Efficacy of guazatine and iminoctadine for control of postharvest decays of oranges. Plant Dis. 72, 906-908.

Bulmer, M.A. Catley, B.J., Kelly, P.J., 1987. The effect of ammonium ions and pH on the elaboration of the fungi extracellular polysaccharide pullulan, by Aur eobasidium pullulans. Appl. Microbiol. Biotechnol. 25, 362-365.

Butler, E.E., Fogle, D., Miranda, M., 1988. Galactomyces citri-aurantii, a newly found téleomorphe of Geotrichum citri-aurantii the cause of sour rot of citrus fruit. Mycotaxon Ithaca 33, 197-212.

Chi, M., Li, G.K., Liu, Y.S., Liu, G.Q., Li, M., Zhang, X.J., Sun, Z.Q., Sui, Y., Liu, J., 2015 Increase in antioxidant enzyme activity, stress tolerance and biocontrol efficacy of Pichia kudriavzevii with the transition from a yeast-like to biofilm morphology. Biol. Control 90, 113-119.

Conrad, M., Schothorst, J., KankipatI, N., Zeebroeck, G.V., Rubio-Texeira, M. Thevelein, J.M., 2014. Nutrient sensing and signaling in the yeast Saccharomyces cerevisiae. FEMS Microbiol. Rev. 38, 254-299.

Di Francesco, A., Ugolini, L., Lazzeri, L., Mari, M., 2015a. Production of volatile organic compounds by Aureobasidium pullulans as a potential mechanism of action against postharvest fruit pathogens. Biol. Control 81, 8-14.

Di Francesco, A., Roberti, R., Martini, C., Baraldi, E., Mari, M., 2015b. Activities of Aureobasidium pullulans cell filtrates against Monilinia laxa of peaches. Microbiol. Res. 181, 61-67.

Droby, S., Wisniewski, M., El-Ghaouth, A., Wilson, C., 2003. Influence of food additives on the control of postharvest rots of apple and peach and efficacy of the yeast-based biocontrol product aspire. Postharvest Biol. Technol. 27, 127-135.

Droby, S., Wisniewski, M., Macarasin, D., Wilson, C., 2009. Twenty years of post harvest biocontrol research: is it time for a new paradigm? Postharvest Biol Technol. 52, 137-145.

Feng, L., Wu, F., Li, J., Jiang, Y., Duan, X., 2011. Antifungal activities of Polyhexamethylene biguanide and Polyhexamethylene guanide against the citrus sour rot pathogen Geotrichum citri-aurantii in vitro and in vivo. Postharvest Biol. Technol. 61, 160-164.

Ferraz, L.P., Cunha, T., Silva, A.L., Kupper, K.C., 2016. Biocontrol ability and putative mode of action of yeasts against Geotrichum citri-aurantii in citrus fruit. Microbiol. Res. 188, 72-79.

Finkel, J.S., Mitchell, A.P., 2011. Genetic control of Candida albicans biofilm development. Nat. Rev. Microbiol. 9, 109-118.

Hao, W., Zhong, G., Hu, M., Luo, J., Weng, Q., Rizwanul- Haq, M., 2010. Control of citrus postharvest green and blue mold and sour rot by tea saponin combined with imazalil and prochloraz. Postharvest Biol. Technol. 56, 39-43.

Ippolito, A., El Ghaouth, A., Wilson, C.L., Wisniewski, M., 2000. Control of postharvest decay of apple fruit by Aureobasidium pullulans and induction of defense responses. Postharvest Biol. Technol. 19, 265-272.

Jiang, L., Wu, S., Moon Kim, J., 2011. Effect of different nitrogen sources on activities of UDPG-pyrophosphorylase involved in pullulan synthesis and pullulan production by Aureobasidium pullulans. Carbohydr. Polym. 86, 1085-1088.

Karim, H., Boubaker, H., Askarne, L., Talibi, I., Msanda, F., Boudyach, E.H., Saadi, B., Ait Ben Aoumar, A., 2015. Antifungal properties of organic extracts of eight Cistus L. species against postharvest citrus sour rot. Lett. Appl. Microbiol. 1, 16-22.
Li, G., Chi, M., Chen, H., Sui, Y., Li, Y., Liu, Y., Zhang, X., Sun, Z., Liu, G., Wang, Q., Liu, J., 2015. Stress tolerance and biocontrol performance of the yeast antagonist, Candida diversa, change with morphology transition. Environ. Sci. Pollut. Res. $23,1-6$.

Lima, J.R., Gondime, D.M.F., Oliveira, J.T.A., Oliveira, F.S.A., Gonçalves, L.R.B., Viana, F.M.P., 2013. Use of killer yeast in the management of postharvest papaya anthracnose. Postharvest Biol. Technol. 83, 58-64.

Liu, X., Wang, J., Gou, P., Mao, C., Zhun, Z., Li, H., 2007. In vitro inhibition of postharvest pathogens of fruit and control of gray mold of strawberry and green mold of citrus by aureobasidin A. Int. J. Food Microbiol. 119, 223-229.

Liu, X., Wang, L.P., Li, Y.C., Li, H.Y., Yu, T., Zheng, X.D., 2009. Antifungal activity of thyme oil against Geotrichum citri-aurantii in vitro and in vivo. J. Appl. Microbiol. $107,1450-1456$.

Liu, X., Fang, W., Liu, L., Yu, T., Lou, B., Zheng, X., 2010. Biological control of postharvest sour rot of citrus by two antagonistic yeasts. Lett. Appl. Microbiol. 51, 30-35.

Liu, J., Sui, Y., Wisniewski, M., Droby, S., Liu, Y., 2013. Review: utilization of antagonistic yeasts to manage postharvest fungal diseases of fruit. Int. J. Food Microbiol. 167, 153-160.

Liu, J., Sui, Y., Wisniewski, M., Xie, Z., Liu, Y., You, Y., Zhang, X., Sun, Z., Li, W., Li, Y., Wang, Q., 2017. The impact of the postharvest environment on the viability and virulence of decay fungi. Crit. Rev. Food Sci. Nutr. http://dx.doi.org/10.1080/ 10408398.2017.1279122.

Luo, Y., Zeng, K., Ming, J., 2012. Control of blue and green mold decay of citrus fruit by Pichia membranefaciens and induction of defense responses. Sci. Hort. 135, 120-127.

Mari, M., Martini, C., Spadoni, A., Rouissi, W., Bertolini, P., 2012. Biocontrol of apple postharvest decay by Aureobasidium pullulans. Postharvest Biol. Technol. 73, 56-62.

McKay, A.H., Föster, H., Adaskaveg, J., 2012. Efficacy and application strategies for propiconazole as a new postharvest fungicide for managing sour rot and green mold of citrus fruit. Plant Dis. 96, 235-242.

Mekbib, S.B., Regnier, T.J.C., Korsten, L., 2011. Efficacy and mode of action of yeast antagonists for control of Penicillium digitatum in oranges. Trop. Plant Pathol. $36,233-240$.

Nielsen, J., 1997. Primary metabolism: transport of ammonia, sulfate and phosphate. In: Physiological Engineering Aspects of Penicillium chrysogenum. W. Scientific, 288pp.

Ouedraogo, N., Savadogo, A., Somda, M.K., Tapsoba, F., Zongo, C., Traore, A.S., 2017. Effect of mineral salts and nitrogen source on yeast (Candida utilis NOY1) biomass production using tubers wastes. Afr. J. Biotechnol. 16, 359-365.

O'Toole, G.A., Kolter, R., 1998. Initiation of biofilm formation in Pseudomonas fluorescens WCS365 proceeds via multiples, convergent signaling pathways: a genetic analysis. Mol. Microbiol. 28, 449-461.

Parafati, L., Vitale, A., Restuccia, C., Cirvilleri, G., 2015. Biocontrol ability and action mechanism of food-isolated yeast strains against Botrytis cinerea causing postharvest bunch rot of table grape. Food Microbiol. 47, 85-92.

Pu, L., Jingfan, F., Kai, C., Chao-Na, L., Yunjiang, C., 2014. Phenylethanol promotes adhesion and biofilm formation of the antagonistic yeast Kloeckera apiculata for the control of blue mold on citrus. FEMS Yeast Res. 14, 536-546.

Ravella, S.R., Quiñones, T.S., Retter, A., Heiermann, M., Amon, T., Hobbs, P.J., 2010 Extracellular polysaccharide (EPS) production by a novel strain of yeast-like fungus Aureobasidium pullulans. Carbohydr. Polym. 82, 728-732.

Scherm, B., Ortu, G., Muzzu, A., Budroni, M., Arras, G., Migheli, Q., 2003. Biocontrol activity of antagonistic yeasts against Penicillium expansum on apple. J. Plant Pathol. 85, 1-9.

Spadaro, D., 2014. Dissecting the mechanisms of action of biocontrol agents to control postharvest diseases of fruit. In: Sherma, N. (Ed.), Biological Controls for Preventing Food Deterioration: Strategies for Preventing Food Deterioration. Wiley-Blackwell, pp. 69-85.

Spadaro, D., Droby, S., 2016. Development of biocontrol products for postharvest diseases of fruit: the importance of elucidating the mechanisms of action of yeast antagonists. Trends Food Sci. Technol. 47, 39-49.

Talibi, I., Askarne, L., Boubaker, H., Boudyach, E.H., Msanda, F., Saadi, B., Ait Ben Aoumar, A., 2012. Antifungal activity of some Moroccan plants against Geotrichum candidum, the causal agent of postharvest citrus sour rot. Crop Prot. 35 41-46.

Vero, S., Garmendia, G., González, M.B., Garat, M.F., Wisniewski, M., 2009. Aureobasidium pullulans as a biocontrol agent of postharvest pathogens of apples in Uruguay. Biocontrol Sci. Technol. 19, 1033-1049.

Vero, S., Garmendia, G., González, M.B., Bentancur, O., Wisniewski, M., 2013. Evaluation of yeasts obtained from Antarctic soil samples as biocontrol agents for the management of postharvest diseases of apple (Malus xdomestica). FEMS Yeast Res. 13, 189-199.

Wiyono, S., Schulz, D.F., Wolf, G.A., 2008. Improvement of the formulation and antagonistic activity of Pseudomonas fluorescens B5 through selective additives in the pelleting process. Biol. Control 46, 348-357.

Yurlova, N.A., Hoog, G.S., 1997. A new variety of Aureobasidium pullulans characterized by exopolysaccharide structure, nutritional physiology and molecular features. Ant. Leeuw 72, 141-147.

Zhang, D., Spadaro, D., Garibaldi, A., Gullino, M.L., 2010. Efficacy of the antagonist Aureobasidium pullulans PL5 against postharvest pathogens of peach, apple and plum and its modes of action. Biol. Control 54, 172-180.

Zhang, D., Spadaro, D., Garibaldi, A., Gullino, M.L., 2011. Potential biocontrol activity of a strain of Pichia guilliermondii against grey mold of apples and its possible 
modes of action. Biol. Control 57, 193-201.

Zhang, D., Spadaro, D., Valente, S., Garibaldi, A., Gullino, M.L., 2012. Cloning, characterization, expression and antifungal activity of an alkaline serine protease of Aureobasidium pullulans PL5 involved in the biological control of postharvest pathogens. Int. J. Food Microbiol. 153, 453-464

Zhou, Y., Ming, J., Deng, L. Zeng, K., 2014. Effect of Pichia membranaefaciens in combination with salicylic acid on postharvest blue and green mold decay in citrus fruits. Biol. Control 74, 21-29. 